\title{
Pemanfaatan Tanaman Hias Pekarangan Berkhasiat Obat di Kecamatan Tanjung Batu
}

\author{
Trimin Kartika \\ e-mail: triminkartika1969@gmail.com

\begin{abstract}
Program Studi Biologi, Fakultas Matematika dan Ilmu Pengetahuan Alam Universitas PGRI Palembang
\end{abstract}

\begin{abstract}
Research on the utilization of ornamental plants of medicinal yard in Tanjung Batu Subdistrict has been conducted in March until May 2018 in Tanjung Batu, Tanjung Baru Petai, and Pajar Bulan Villages, Tanjung Batu Subdistrict, Ogan Ilir Regency, South Sumatera Province. The objective of the study was to find out the types of ornamental plants used, the part of the plant used as medicine, and the types of diseases that can be treated by ornamental plants. This research used direct orientation method. The results showed that medicinal plants consisted of 27 species, 29 genera, and 29 species. Part of medicinal plants used as raw materials that have medicinal properties in the form of leaves, roots, stems, skin, flowers, seeds, sap. Types of ornamental plants that are utilized as the most widely preserved drug in the village of Tanjung Batu was 68.96\%, in Tanjung Baru Petai Village 62.06\%, while the ornamental plant species used as medicine by the community of Pajar Bulan Village was $48.27 \%$. The percentage of ornamental plant used as medicines by Tanjung Batu sub-district was highest on the leaves $(78.57 \%)$, while the lowest percentage of the sap was $(6.10 \%)$.
\end{abstract}

Keywords: ornamental plants, efficacious drugs, garden, Tanjung Batu, Tanjung Baru Petai, Pajar Bulan

\begin{abstract}
ABSTRAK
Penelitian tentang Pemanfaatan Tanaman Hias Pekarangan berkhasiat obat di Kecamatan Tanjung Batu telah dilakukan pada bulan Maret sampai bulan Mei 2018 di Desa Tanjung Batu, Desa Tanjung Baru Petai, dan Desa Pajar Bulan Kecamatan Tanjung Batu Kabupaten Ogan Ilir Provinsi Sumatera Selatan. Penelitian bertujuan untuk mengetahui jenis-jenis jenis tanaman hias perkarangan yang dimanfaatkan, bagian yang dimanfaatkan sebagai obat, dan jenis-jenis penyakit yang dapat diobati oleh tanaman hias. Penelitian menggunakan metode orientasi langsung. Hasil penelitian menunjukkan bahwa jenis-jenis tumbuhan hias berkhasiat obat terdiri dari 27 familia, 29 genus, dan 29 spesies. Bagian tumbuhan obat yang digunakan sebagai bahan baku yang memiliki khasiat obat berupa daun, akar/rimpang, batang, kulit, bunga, biji, gel dan getah. Jenis tanaman hias yang di manfaatkan sebagai obat yang paling banyak dipelihara di Desa Tanjung Batu sebesar 68,96\%, di Desa Tanjung Baru Petai sebesar 62,06\%, sedangkan jenis tanaman hias yang dimanfaatkan sebagai obat oleh masyarakat Desa Pajar Bulan sebesar 48,27\%. Persentasi bagian tanaman hias yang dimanfaatkan sebagai obat oleh masyarakat kecamatan Tanjung Batu paling tinggi pada bagian daun sebesar $(78,57 \%)$, sedangkan persentase terendah pada bagian getah yaitu $(6.10 \%)$.
\end{abstract}

Kata Kunci: tanaman hias, berkhasiat obat, pekarangan, Desa Tanjung Batu, Tanjung Baru Petai, Pajar Bulan 


\section{PENDAHULUAN}

Tumbuhan berkhasiat obat adalah jenis tumbuhan yang pada bagian-bagian tertentu baik akar, batang, kulit, daun maupun hasil ekskresinya dipercaya dapat menyembuhkan atau mengurangi rasa sakit (Noorhidayah \& Sidiyasa, 2006). Saat ini, upaya pengobatan dengan bahanbahan alam berkembang pesat. Perkembangan pemanfaatan tumbuhan obat sangat prospektif ditinjau dari berbagai faktor pendukung, seperti tersedianya sumberdaya hayati yang kaya dan beranekaragam di Indonesia.

Utami (2013) menjelaskan bahwa "Tumbuhan obat adalah suatu jenis tumbuhan yang sebagian, seluruh tumbuhan, dan eksudat (sel) tumbuhan tersebut digunakan sebagai obat, bahan, atau ramuan obat-obatan". Tumbuhan obat sudah lama dikenal dan dimanfaatkan oleh masyarakat dalam kehidupan sehari-hari.

Pemanfaatan tanaman hias sebagai obat dilakukan oleh masyarakat Desa Tanjung Batu, Desa Tanjung Baru Petai, dan Desa Pajar Bulan Kecamatan Tanjung Batu secara spesifik masyarakat memanfaatkan potensi tanaman hias sebagai pengobatan alternatif.

Dari beberapa jenis tanaman yang ditemukan di masyaraakat diantaranya memiliki nilai ekonomis yang tinggi, seperti anggrek, melati dan mawar. Namun masih banyak jenis tanaman hiasyang belum dimanfaatkan secara optimal dari sisi nilai ekonomisnya diantaranya tanaman hias tersebut ternyata memiliki khasiat obat. (Bambang \& Heru.2011).

Kebutuhan tanaman hias dirumah maupun ditempat lain sangat tergantung pada kondisi masyarakat suatu daerah. Semakin tinggi tingkat pengetahuan masyarakat semakin tinggi pula pemahaman tentang manfaat tanaman hias.

Beberapa jenis tanaman hias memiliki fungsi ganda yaitu selain sebagai tanaman hias, juga sebagai bahan obat untuk beberapa penyakit yang lazim ditemukan masyarakat. Manfaat dari masing-masing tanaman hias tersebut tidak sama karena kandungan di dalamnya berbeda, namun kandungan yang berbeda tersebut dibuat ramuan. Ramuan obat dari tanaman hias di buat dengan aturan, ramuan tersebut tidak menimbulkan efek yang merugikan pemakainnya, karena umumnya ramua bersifat alami dan tradisional. (Bambang \& Heru.2011).

Obat trandisional yang berasal dari tanaman memiliki efek samping yang jauh lebih rendah tingkat bahayanya dibandingkan obat-obatan kimia, selain murah dan mudah diperoleh. Hal ini disebabkan efek dari tanaman obat bersifat alami, tidak sekeras efek obatobatan kimia.(Fauziah.2007)

Pemanfaatan tumbuhan obat masih dianggap berperan penting terutama bagi masyarakat Kecamatan Tanjung Batu Kabupaten Ogan Ilir (OI), khususnya masyarakat Desa Tanjung Batu, masyarakat Tanjung Baru Petai dan masyarakat Pajar Bulan. Peneliti diharapkan memberikan informasi kepada masyarakat tentang pemnfaatan tanaman hias pekarangan dapat dijadikan sebagai obat tradisional dalam pengobatan alternatif.

\section{BAHAN DAN METODE}

Penelitian dilaksanakan pada bulan Maret sampai Mei 2018 di Kecamatan Tanjung Batu Kabupaten Ogan Ilir (OI) Sumatera Selatan. Bahan yang digunakan dalam penelitian ini yaitu jenis-jenis tanaman hias di pekarang rumah.

Pengumpulan data dilakukan dengan cara survei eksploratif yaitu wawancara dan pengamatan langsung di lapangan. Sampel yang didapat berdasarkan hasil wawancara secara semi terstruktur dan quisioner dengan masyarakat yang menanam tanaman hias 
dan memang mengetahui tanaman hias dapat dimanfaatkan sebagai obat. Jumlah responden 20 orang masyarakat perdesa yaitu masyarakat desa Tanjung Batu, masyarakat desa dan masyarakat desa Pajar Bulan. Untuk mengetahui potensi tanaman hias berkhasiat di Kecamatan Tanjung Batu dilakukan dengan cara identifikasi melalui pengamatan langsung di lapangan dan setiap tanaman hias berkhasiat obat dicatat nama lokalnya, bagian yang digunakan, serta cara memanfaatkan dan pemanfaatannya, jenis penyakit yang diobati, ekonomi masyarakat. Sampel Tanaman hias dipekarangan dan sekitar pekarangan rumah masyarakat. Identifikasi Tanaman hias berkhasiat obat selain informasi dari masyarakat juga menggunakan literatur tentang khasiat tanaman obat yaitu Azzymi tahun 2016. Hasil yang didapatkan kemudian dianalisis menggunakan analisis deskriptif.

\section{HASIL DAN PEMBAHASAN}

Hasil penelitian di Kecamatan Tanjung Batu Kabupaten Ogan Ilir (OI) yaitu di Desa Tanjung Batu, Tanjung Baru Petai dan Pajar Bulan ditemukan 26 familia, 29 genus, dan 29 spesies tanaman hias yang dimanfaatkan sebagai obatobatan oleh masyarakat, disajikan pada Tabel 1.

Tabel 1. Jenis-Jenis Tanaman Hias Berkhasiat Obat di Temukan di Kecamatan Tanjung Batu Ogan Ilir (OI) dan pemanfaatannya

\begin{tabular}{|c|c|c|c|c|}
\hline No & Familya & Genus & Spesies & Nama Lokal \\
\hline 1. & Araceae & Epipremnum & Epipremnum autrum (L). Engl & Sireh Gading \\
\hline 2. & & Anthurium & Anthurium andraeanum L. & Kopeng Gajah \\
\hline 3. & Piperaceae & Piper & Piper betle L. & Sireh \\
\hline 4. & Euphorbiaceae & Codiaeum & Codiaeum variegatum $\mathrm{Bi}$ & Puring \\
\hline 5. & Rosaceae & Rosa & Rosa Hiproida & Mawar \\
\hline 6. & Oleaceae & Jasminum & Jasminum sambac L. & Melati \\
\hline 7. & Asphodelaceae & Aloe & Aloe vera $\mathrm{L}$. & Lida Buaya \\
\hline 8. & Cannaceae & Canna & Canna coccinea $\mathrm{L}$. & Bungo Tasbih \\
\hline 9. & Agavaceae & Sansevieria & Sansevieria Thunb. & Lidah Mertuo \\
\hline 10 . & Rubiaceae & Gardenia & Gardenia augusta Merr. & Kaco Piring \\
\hline 11. & Annonaceae & Cananga & Cananga adorata (Lamk) Hook & Kenanga \\
\hline 12. & Crassulaceae & Bryopyllum & Bryopyllum pinnatum ( Lam) & Cocor Bebek \\
\hline 13. & Acanthaceae & Strobilanthes & Strobilanthes crispa $\mathrm{Bl}$. & Keji Beling \\
\hline 14. & & Pachystachys & Pachystachys lutea $\mathrm{L}$. & Bungo Lilin \\
\hline 15 . & Commelinaceae & Rhoeo & Rhoeo discolor & Adam Hawa \\
\hline 16. & Apcynaceae & Allamanda & Allamanda cthartica $\mathrm{L}$ & Allamanda \\
\hline 17. & Moraceae & Ficus & Ficus benjamina $L$. & Beringin \\
\hline 18. & Caesalpiniaceae & Saraca & Saraca indica & Asoka \\
\hline 19. & Cactaceae & Opuntia & Opuntia cochenillifera & Kaktus \\
\hline 20. & Pteridaceae & Adiantum & Adiantum cuneatum langs \& fisch & Suplir \\
\hline 21. & Malvaceae & Hibicus & Hibicus rosa-sinensis L. & Kembang Sepatu \\
\hline 22. & Lamiaceae & Orthosiphon & Orthosiphon aristatus & Kumis Kucing \\
\hline 23. & Solanaceae & Datura & Datura fastuosa & Kecobong \\
\hline 24. & Apocynacecae & Plumeria & Plumeria acumnita Ait & Kamboja \\
\hline 25. & Astereceae & Helianthus & Helianthus annus L. & Bungo Matoari \\
\hline 26. & Amaranthaceae & Celosia & Celosia argentea $\mathrm{L}$. & Ekor Belando \\
\hline 27. & Nytaginaceae & Bougainvillea & Bougainvillea spinosa $\mathrm{L}$. & Bungo Kertas \\
\hline 28 & Amaryllidaceae & Crynum & Crynum asiaticum L. & Bungo Bakong \\
\hline 29. & Asparagaceae & Cordyline Comm & Cordyline fruticosa (L). A. Chev. & Anjuang \\
\hline
\end{tabular}

Sumber : Wawancara, identifikasi lapangan, dan Azzymi. 2016.

Berdasarkan Tabel 1. Jumlah spesies tanaman hias yang dimanfaatkan oleh masyarakat sebagai obat-obatan di Desa Tanjung Batu ditemukan 20 spesies, yaitu 
: Epipremnum autrum (L). Engl, Piper betle L., Codiaeum variegatum $\mathrm{Bi}$., Rosa Hiproida, Jasminum sambac L., Aloe vera L., Canna coccinea L., Sansevieria Thunb., Gardenia augusta Merr., Bryopyllum pinnatum ( Lam), Strobilanthes crispa B1., Pachystachys lutea L., Allamanda cthartica L., Ficus benjamina L., Opuntia cochenillifera, Adiantum cuneatum langs \& fisch, Hibicus rosa-sinensis L.,Orthosiphon aristatus, Plumeria acumnita Ait, Celosia argentea L., dan Cordyline fruticosa (L). A. Chev., di desa Tanjung Baru Petai ditemukan 18 spesies yaitu: Epipremnum autrum (L). Engl, Anthurium andraeanum L., Piper betle L., Rosa Hiproida, Aloe vera L., Canna coccinea L., Gardenia augusta Merr., Cananga adorata (Lamk) Hook., Strobilanthes crispa Bl., Rhoeo discolor, Allamanda cthartica L., Opuntia cochenillifera, Hibicus rosa-sinensis L.,
Orthosiphon aristatus, Plumeria acumnita Ait, Helianthus annus L., Crynum asiaticum L., dan bunga Cordyline fruticosa (L). A. Chev., sedangkan di Desa Pajar Bulan ditemukan 13 spesies yaitu : Piper betle L., Rosa Hiproida, Aloe vera L., Canna coccinea L., Strobilanthes crispa B1., Allamanda cthartica L., Hibicus rosa-sinensis L., Datura fastuosa, Plumeria acumnita Ait, Bougainvillea spinosa L., Crynum asiaticum L., dan Cordyline fruticosa (L). A. Chev.

Pemanfaatan jenis-jenis tanaman hias sebagai obat-obatan yang dipelihara dipekarangan dan sekitar rumah masyarakat Desa Tanjung Batu, masyarakat Desa Tanjung Batu Petai, dan masyarakat Desa Pajar Bulan Kecamatan Tanjung Batu Kabupaten Ogan Ilir (OI) disajikan pada Gambar 1.

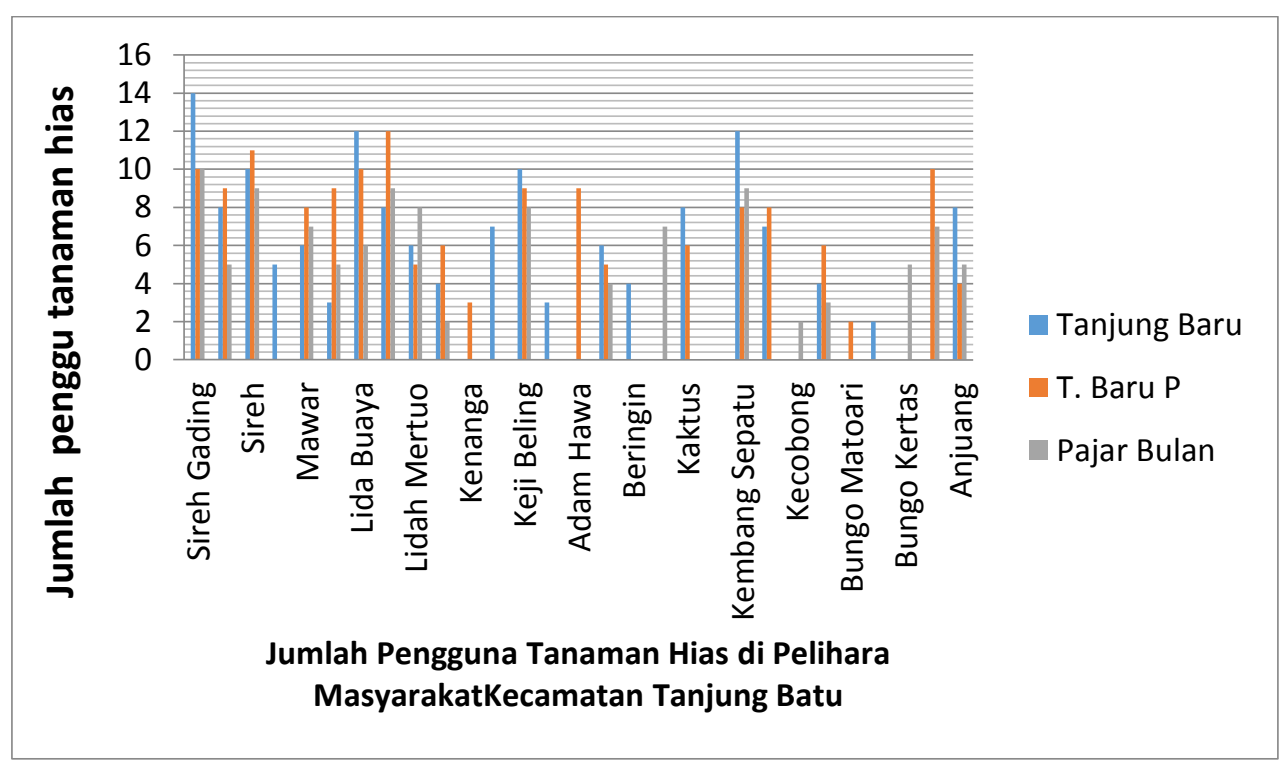

Gambar 1. Jumlah Pengguna Tanaman Hias sebagai Obat di Kecamatan Tanjung Batu Kabupaten Ogan Ilir (OI)

Berdasarkan Gambar 1. Jumlah pengguna tanaman hias yang dimanfaatkan sebagai obat oleh masyarakat Desa Tanjung Batu sebagian tanaman lebih tinggi jumlahnya di banding Desa lain, sedangkan tanaman hias di Desa Pajar bulan hampir semua tanaman hias yang dipelihara lebih sedikit jumlahnya. Jenis tanaman hias yang di manfaatkan sebagai obat yang paling banyak dipelihara di Desa Tanjung Batu sebesar 68,96\%, di Desa Tanjung Baru Petai sebesar $62,06 \%$, sedangkan jenis tanaman hias yang dimanfaatkan sebagai obat oleh masyarakat Desa Pajar Bulan sebesar 48,27\%. Masyarakat kecamatan Tanjung Batu masih kurang kurang pengetahuannya disamping untuk keindahkan lingkungan rumah, ternyata 
tanaman hias mempunyai khasiat sebagai obat, selain itu ada tanaman hias yang bermafaat untuk menyerap timbal seperti Puring (Codiaeum variegatum $\mathrm{Bi}$ ), dan tanaman hias lida mertua (Sansevieria Thunb.) dapat menyerap polusi. Masyarakat Desa Tanjung Batu memiliki nilai persentasi tertinggi memelihara tanaman hias dipekarangan rumahnya, berdasarkan hasil wawancara masyarakat tersebut memang sebagian mengetahui bahwa tanaman yang dipeliharanya mempunyai khasiat obat. Bagian tanaman hias yang dimanfaatkan sebagai obatobatan disajikan pada Tabel 2.

Tabel 2. Jenis Bagian Tanaman Hias yang Dimanfaatkan oleh Masyarakat di Kecamatan Tanjung Batu Ogan Ilir (OI).

\begin{tabular}{|c|c|c|c|c|c|c|}
\hline \multirow[t]{2}{*}{ No } & \multirow[t]{2}{*}{ Nama Lokal } & \multirow[t]{2}{*}{ Spesies } & \multirow{2}{*}{$\begin{array}{c}\text { Bagian Tanaman Hias } \\
\text { yang dimanfaatkan }\end{array}$} & \multicolumn{3}{|c|}{ Desa } \\
\hline & & & & Tanjung Batu & Tjg Baru .P & Pajar Bulan \\
\hline 1. & Sireh Gading & Epipremnum autrum (L). Engl & Daun, kulit, batang, biji & $\sqrt{1}$ & $\sqrt{1}$ & $\sqrt{1}$ \\
\hline 2. & Kopeng Gajah & Anthurium andraeanum L. & Daun, batang & & $\sqrt{ }$ & \\
\hline 3. & Sireh & Piper betle L. & Daun & $\sqrt{ }$ & $\sqrt{ }$ & $\sqrt{ }$ \\
\hline 4. & Puring & Codiaeum variegatum $\mathrm{Bi}$ & Daun & $\sqrt{ }$ & & \\
\hline 5. & Mawar & Rosa Hiproida & Daun, akar, bunga & $\sqrt{ }$ & $\sqrt{ }$ & $\sqrt{ }$ \\
\hline 6. & Melati & Iasminum sambac L. & Bunga & $\sqrt{ }$ & & \\
\hline 7. & Lida Buaya & Aloe vera $\mathrm{L}$. & Gel, lateks & $\sqrt{ }$ & $\sqrt{ }$ & $\sqrt{ }$ \\
\hline 8. & Bungo Tasbih & Canna coccinea $\mathrm{L}$. & Bunga, akar, biji & $\sqrt{ }$ & $\sqrt{ }$ & $\sqrt{ }$ \\
\hline 9. & Lidah Mertuo & Sansevieria Thunb. & Daun, akar, getah & $\sqrt{ }$ & & \\
\hline 10. & Kaco Piring & Gardenia augusta Merr. & Bunga & $\sqrt{ }$ & $\sqrt{ }$ & $\sqrt{ }$ \\
\hline 11. & Kenanga & Cananga adorata (Lamk) Hook & Daun, kulit, bunga & & $\sqrt{ }$ & \\
\hline 12. & Cocor Bebek & Bryopyllum pinnatum ( Lam) & Daun & $\sqrt{ }$ & & \\
\hline 13. & Keji Beling & Strobilanthes crispa Bl. & Daun & $\sqrt{ }$ & $\sqrt{ }$ & $\sqrt{ }$ \\
\hline 14. & Bungo Lilin & Pachystachys lutea $\mathrm{L}$. & Daun, akar, bunga & $\sqrt{ }$ & & \\
\hline 15. & Adam Hawa & Rhoeo discolor & Daun & & $\sqrt{ }$ & \\
\hline 16. & Allamanda & Allamanda cthartica $\mathrm{L}$ & Daun, bunga, getah & $\sqrt{ }$ & $\sqrt{ }$ & $\sqrt{ }$ \\
\hline 17. & Beringin & Ficus benjamina L. & Daun & $\sqrt{ }$ & & \\
\hline 18. & Asoka & Saraca indica & Daun, bunga & & & $\sqrt{ }$ \\
\hline 19. & Kaktus & Opuntia cochenillifera & Daun & $\sqrt{ }$ & $\sqrt{ }$ & \\
\hline 20. & Suplir & Adiantum cuneatum langs \& fisch & Daun & $\sqrt{ }$ & & \\
\hline 21. & Kembang Sepatu & Hibicus rosa-sinensis L. & Daun, bunga, akar & $\sqrt{ }$ & $\sqrt{ }$ & $\sqrt{ }$ \\
\hline 22. & Kumis Kucing & Orthosiphon aristatus & Seluruh bagian tanaman & $\sqrt{ }$ & $\sqrt{ }$ & \\
\hline 23. & Kecobong & Datura fastuosa & Daun, bunga & & & $\sqrt{ }$ \\
\hline 24. & Kamboja & Plumeria acumnita Ait & Daun, batang, getah,akar & $\sqrt{ }$ & $\sqrt{ }$ & $\sqrt{ }$ \\
\hline 25. & Bungo Matoari & Helianthus annus L. & Bunga, biji & & $\sqrt{ }$ & \\
\hline 26. & Ekor Belando & Celosia argentea $\mathrm{L}$. & Seluruh bagian tanaman & $\sqrt{ }$ & & \\
\hline 27. & Bungo Kertas & Bougainvillea spinosa L. & Bunga, batang & & & $\sqrt{ }$ \\
\hline 28 & Bungo Bakong & Crynum asiaticum L. & Umbi, akar, bunga, biji & & $\sqrt{ }$ & $\sqrt{ }$ \\
\hline 29. & Anjuang & Cordyline fruticosa (L). A. Chev. & Daun & $\sqrt{ }$ & $\sqrt{ }$ & $\sqrt{ }$ \\
\hline
\end{tabular}

Pada Tabel 2. Pemanfaatan bagian tanaman hias sebagai obat yang paling banyak dimanfaatkan pada bagian daun sebanyak 22 spesies, bagian bunga 15 spesies, bagian batang 6 spesies, bagian biji 6 spesies, bagian kulit 4 spesies dan bagian yang sedikit dimanfaatkan yaitu bagian getah tanaman hias 2 spesies, cara penggunaan tanaman hias sebagai obat dengan cara di buat ekstrak, direbus, dikeringkan dibuat teh, dan dipoles sebagai minyak atsiri. Persentase bagian tanaman yang dimanfaatkan sebagai obat disajikan pada Gambar 2. 


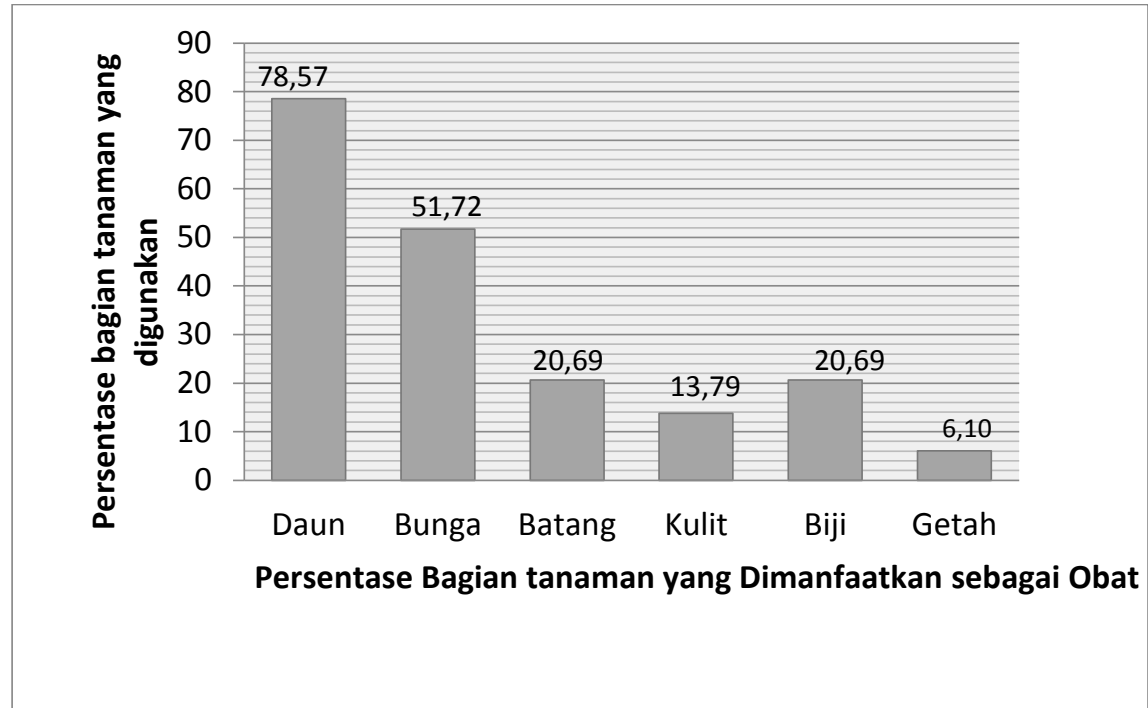

Gambar 2. Persentase Bagian tanaman Hias yang Dimanfaatkan sebagai Obat

Pada Gambar 2. Persentasi bagian tanaman hias yang dimanfaatkan sebagai obat oleh masyarakat kecamatan Tanjung Batu paling tinggi pada bagian daun sebesar $(78,57 \%)$, sedangkan persentase terendah pada bagian getah yaitu $(6.10 \%)$. Masyarakat kecamatan Tanjung Batu memanfaatkan tanaman hias yang ada disekitar pekarangan rumah memiliki khasiat obat dalam menyembuhkan berbagai penyakit. Bagian dari tanaman yang dijadikan obat oleh masyarakat Desa Tanjung Batu, masyarakat Desa Tanjung Baru Petai, dan masyarakat Pajar Bulan yaitu bagian akar, batang, daun, bunga, biji, getah, kuli, bagian yang paling sering digunakan sebagai obat adalah daun. Menurut Setyowati (2010) dalam menjelaskan, bahwa bagian daun paling sering digunakan karena bagian daun paling mudah di dapatkan bila dibandingkan dengan bagian lain.

Masyarakat kecamatan Tanjung Batu yaitu masyarakat Desa Tanjung Batu, Desa Tanjung Baru Petai dan masyarakat Desa Pajar Bulan memanfaatkan tanaman hias yang ada dipekarangan rumah dan sekitar sebagai obat disajikan pada Tabel 3.

Tabel 3. Pemanfaatan bagian jenis tanaman Hias yang Dimanfaatkan oleh Masyarakat di Kecamatan Tanjung Batu Ogan Ilir (OI) sebagai obat.

\begin{tabular}{|c|c|c|c|c|}
\hline No & Nama Lokal & Spesies & $\begin{array}{l}\text { Bagian yang } \\
\text { dimanfaatkan }\end{array}$ & $\begin{array}{c}\text { Pemanfaatan Bagian } \\
\text { Tanaman Hias }\end{array}$ \\
\hline 1. & Sireh Gading & Epipremnum autrum (L). Engl & $\begin{array}{l}\text { Daun, kulit, } \\
\text { batang, biji }\end{array}$ & $\begin{array}{l}\text { Mengatasi haid tidak lancar, reumatik,cacing } \\
\text { keremi }\end{array}$ \\
\hline 2. & Kopeng Gajah & Anthurium andraeanum $\mathrm{L}$. & Daun, batang & Bengkak pada tenggorokan \\
\hline 3. & Sireh & Piper betle L. & Daun & $\begin{array}{l}\text { Keputihan, diare, gatal,gatal, menghilangkan } \\
\text { bau mulut }\end{array}$ \\
\hline 4. & Puring & Codiaeum variegatum $\mathrm{Bi}$ & Daun & Spilis, sakit perut, sukar berkeringat \\
\hline 5. & Mawar & Rosa Hiproida & $\begin{array}{l}\text { Daun, } \\
\text { bunga }\end{array}$ & $\begin{array}{l}\text { Melancarkan haid, keputihan, sakit kepala, } \\
\text { disentri, batuk darah, reumatik }\end{array}$ \\
\hline
\end{tabular}




\begin{tabular}{|c|c|c|c|c|}
\hline 6. & Melati & lasminum sambac L. & Bunga & $\begin{array}{l}\text { Menggurangi produksi ASI, sesak napas, } \\
\text { radang usus }\end{array}$ \\
\hline 7. & Lida Buaya & Aloe vera $\mathrm{L}$. & Gel, lateks & $\begin{array}{l}\text { Iritasi dan gatal-gatal pada kulit, diabetes, } \\
\text { asma, demam panas }\end{array}$ \\
\hline 8. & Bungo Tasbih & Canna coccinea $\mathrm{L}$. & $\begin{array}{l}\text { Bunga, akar, } \\
\text { biji }\end{array}$ & $\begin{array}{l}\text { Disentri, haid terlalu banyak, batuk darah, } \\
\text { menghentikan pendarahan, sakit kuning }\end{array}$ \\
\hline 9. & Lidah Mertuo & Sansevieria Thunb. & $\begin{array}{l}\text { Daun, akar, } \\
\text { getah }\end{array}$ & $\begin{array}{l}\text { Obat sakit gigi, mencegah diabetes, sakit } \\
\text { kepala, anti septik }\end{array}$ \\
\hline 10. & Kaco Piring & Gardenia augusta Merr. & Bunga & Diabetes, sariawan, demam \\
\hline 11. & Kenanga & Cananga adorata (Lamk) Hook & $\begin{array}{l}\text { Daun, } \\
\text { bunga }\end{array}$ & Hipertensi, asma, malaria \\
\hline 12. & Cocor Bebek & Bryopyllum pinnatum ( Lam) & Daun & Mengobati demam panas, sakit kepala, batuk \\
\hline 13. & Keji Beling & Strobilanthes crispa B1. & Daun & Kencing manis, ginjal, reumatik, ginjal. \\
\hline 14. & Bungo Lilin & Pachystachys lutea $\mathrm{L}$. & $\begin{array}{l}\text { Daun, } \\
\text { bunga }\end{array}$ & Diare, cacingan pada anak-anak \\
\hline 15. & Adam Hawa & Rhoeo discolor & Daun & Reumatik, diare, batuk darah, disentri \\
\hline 16. & Allamanda & 4llamanda cthartica $\mathrm{L}$ & $\begin{array}{l}\text { Daun, bunga, } \\
\text { getah }\end{array}$ & Penyakit malaria, kuning, gigitan ular berbisa \\
\hline 17. & Beringin & Ficus benjamina L. & Daun & Reumatik, disentri, malaria, asma, diare \\
\hline 18. & Asoka & Saraca indica & Daun, bunga & Mentrusri tidak teratur, disentri, wasir \\
\hline 19. & Kaktus & Opuntia cochenillifera & Daun & $\begin{array}{l}\text { Menurunkan berat badan, mencegah diabetes, } \\
\text { anti kanker }\end{array}$ \\
\hline 20. & Suplir & Adiantum cuneatum langs \& fisch & Daun & Memperlancar air seni, obat cacing \\
\hline 21. & Bungo & Hibicus rosa-sinensis L. & $\begin{array}{l}\text { Daun, bunga, } \\
\text { akar }\end{array}$ & $\begin{array}{l}\text { TBC, batuk darah, demam, keputihan, } \\
\text { melancarkan haid }\end{array}$ \\
\hline 22. & Kumis Kucing & Orthosiphon aristatus & $\begin{array}{l}\text { Seluruh bagian } \\
\text { tanaman }\end{array}$ & $\begin{array}{l}\text { Kencing batu, demam, keputihan, peluruh } \\
\text { kencing }\end{array}$ \\
\hline 23. & Kecobong & Datura fastuosa & Daun, bunga & Asma, reumatik, sembelit, sakit pinggang \\
\hline 24. & Kamboja & Plumeria acumnita Ait & $\begin{array}{l}\text { Daun, batang, } \\
\text { getah,akar }\end{array}$ & $\begin{array}{l}\text { Disentri, menghentikan batuk, meredam } \\
\text { demam, penurun panas, sakit kepala }\end{array}$ \\
\hline 25. & Bungo Matoari & Helianthus annus L. & Bunga, biji & Menurunkan hipertensi, sakit kepala, rematik \\
\hline 26. & Ekor Belando & Celosia argentea $\mathrm{L}$. & $\begin{array}{l}\text { Seluruh bagian } \\
\text { tanaman }\end{array}$ & $\begin{array}{l}\text { Mengobati hipertensi, keputihan, muntah } \\
\text { darah }\end{array}$ \\
\hline 27. & Bungo Kertas & Bougainvillea spinosa $\mathrm{L}$. & Bunga, batang & $\begin{array}{l}\text { Mengobati bisul, gatal-gatal, melancarkan } \\
\text { haid, keputihan }\end{array}$ \\
\hline 28 & Bungo Bakong & Crynum asiaticum L. & $\begin{array}{l}\text { Umbi, akar, } \\
\text { bunga, biji }\end{array}$ & $\begin{array}{l}\text { Mengobati luka, borok, peluruh kencing, } \\
\text { reumatik }\end{array}$ \\
\hline 29. & Anjuang & Cordyline fruticosa (L). A. Chev. & Daun & $\begin{array}{l}\text { Menghentikan pendarahan, menghancurkan } \\
\text { darah beku }\end{array}$ \\
\hline
\end{tabular}

Pada Tabel 3. Jenis penyakit yang dapat disembuhkan dengan memakai ramuan bagian tanaman hias dengan cara direbusyang dimanfaatkan sebagai obat dapat menyembuhkan penyakit reumatik, cacing keremi, mengatasi haid tidak lancar, bengkak pada tenggorokan, keputihan, diare, gatal-gatal, menghilangkan bau mulut, spilis, sakit perut, sukar berkeringat, keputihan, sakit kepala, disentri, batuk darah, mengurangi produksi ASI, sesak napas, radang usus, diabetes, asmma, demam panas, sakit kuning, , obat sakit gigi, obat sakit gigi, sakit kepala, anti septik, sariawan, hipertensi, kencing manis, ginjal, malaria, gigitan uar berbisa, wasir, menurunkan berat badan, anti kanker, melancarkan air seni, TBC, peluruh kencing, sembelit, sakit pinggang, muntah darah, mengobati bisul, mengobati luka, borok, peluruh kencing, dan menghancurkan darah beku.

Jumlah jenis tanaman hias yang dimanfaatkan untuk mengobati penyakit reumatik ada 8 spesies yaitu Epipremnum autrum (L). Engl, Rosa Hiproida, Strobilanthes crispa Bl., Rhoeo discolor, Ficus benjamina L., Datura fastuosa, Helianthus annus L., dan Crynum asiaticum L., sedangkan jumlah jenis tanaman yang dimanfaatkan mengobati 
penyakit keputihan ada 6 spesies yaitu: Piper betle L., Rosa Hiproida, Hibicus rosa-sinensis L., Orthosiphon aristatus, Celosia argentea L., dan Bougainvillea spinosa L. Jenis tanaman lain yang dimanfaatkan sebagai obat untuk menyembuhkan berbagai penyakit.

\section{KESIMPULAN}

Dari hasil penelitian Pemanfaatan Tanaman Hias Pekarangan Berkhasiat Obat yang telah dilakukan di Desa Tanjung Batu, Desa Tanjung Baru Petai, dan Desa Pajar Bulan dapat diambil kesimpulan sebagai berikut:

1. Ditemukan 26 familia, 29 genus, dan 29 spesies tanaman hias yang dimanfaatkan sebagai obat-obatan oleh masyarakat

2. Persentasi bagian tanaman hias yang dimanfaatkan sebagai obat oleh masyarakat kecamatan Tanjung Batu paling tinggi pada bagian daun sebesar $(78,57 \%)$, sedangkan persentase terendah pada bagian getah yaitu $(6.10 \%)$.

\section{DAFTAR PUSTAKA}

Azzamy. 2016. 250 Jenis Tanaman Obat Lengkap dengan Manfaat dan Khasiat.(Http:mitalom.com/author/ Azzmy). Diakses 05 Juni 2017.

Noorhidayah \& Sidiyasa, K.(2006). Konservasi Ulin (Eusideroxylon zwageriTeijsm \& Binn.) dan Pemanfaatannya sebagai Tumbuhan Obat. Info Hutan III (2).

Setyowati, W.A.E, dkk. (2014), Skrining Fitokimia dan Identifikasi Komponen Utama Ekstrak Metanol Kulit Durian (Durian zibethinus Murr) Varietas Petruk. Jurnal Seminar Nasional Kimia dan Pendidikan Kimia VI. ISBN (97936375).
Utami, P. 2013. Diet Aman dan Sehat Berkat Herbal. Jakarta : Fmedia

Muhlisah, F,. 2007. Tanaman Obat Keluarga. Penerbit Swadaya. Jakarta.

Mursito, B.\&, H. 2011. Tanaman Hias Berkhasiat Obat. Penebar Swadaya.Jakarta 